\title{
Commissioning of the CMS Magnet
}

Domenico Campi, Benoit Curé, Andrea Gaddi, Hubert Gerwig, Alain Hervé, Vyacheslav Klyukhin, Gilles Maire, Goran Perinic, Philippe Brédy, Philippe Fazilleau, Francois Kircher, Bruno Levésy, Pasquale Fabbricatore, Stefania Farinon, and Michela Greco

\begin{abstract}
CMS (Compact Muon Solenoid) is one of the large experiments for the LHC at CERN. The superconducting magnet for CMS has been designed to reach a $4 \mathrm{~T}$ field in a free bore of $6 \mathrm{~m}$ diameter and $12.5 \mathrm{~m}$ length with a stored energy of $2.6 \mathrm{GJ}$ at full current.

The flux is returned through a $10000 \mathrm{t}$ yoke comprising of five wheels and two end caps composed of three disks each.

The magnet was designed to be assembled and tested in a surface hall, prior to be lowered at $90 \mathrm{~m}$ below ground, to its final position in the experimental cavern.

The distinctive feature of the cold mass is the four-layer winding, made from a reinforced and stabilized NbTi conductor.

The design and construction was carried out by CMS participating institutes through technical and contractual endeavors. Among them CEA Saclay, INFN Genova, ETH Zurich, Fermilab, ITEP Moscow, University of Wisconsin and CERN.

The construction of the CMS Magnet, and of the coil in particular, has been completed last year. The magnet has just been powered to full field achieving electrical commissioning.

After a brief reminder of the design and construction the first results of the commissioning are reported in this paper.
\end{abstract}

Index Terms-CMS, commissioning, LHC, magnet, solenoid.

\section{INTRODUCTION}

C MS is a general-purpose proton-proton detector designed to run at the highest luminosity at the LHC at CERN. The design of such a detector includes a high solenoidal magnetic field of $4 \mathrm{~T}$ generated by a superconducting coil [1], [2].

The requirements of good momentum resolution for particles, muons in particular, lead to the choice of a $12.5 \mathrm{~m}$ long solenoid and a free bore of $6 \mathrm{~m}$ with a uniform magnetic field of $4 \mathrm{~T}$. The inner diameter of the coil is large enough to install the tracking system and the full calorimetry. The muon spectrometers are housed within the elements of the return yoke, in a four-layer configuration. The yoke is designed to return the flux in saturation through a $1.5 \mathrm{~m}$ iron thickness.

CMS is an international collaboration comprising more than 130 High Energy Physics Institutes from 36 countries. The magnet is a common project of CMS in the sense that it has

Manuscript received August 29, 2006.

D. Campi, B. Curé, A. Gaddi, H. Gerwig, A. Hervé, V. Klyukhin, G. Maire, and G. Perinic are with the CERN Geneva, Switzerland.

P. Brédy, P. Fazilleau, F. Kircher, and B. Levésy are with CEA/DAPNIA Saclay, France.

P. Fabbricatore, S. Farinon, and M. Greco are with INFN-Genova, 16146 Genova, Italy (e-mail: Pasquale.Fabbricatore@ge.infn.it).

Color versions of one or more of the figures in this paper are available online at http://ieeexplore.ieee.org.

Digital Object Identifier 10.1109/TASC.2007.897754 been financed by all participating institutes. Some of them have taken direct responsibilities in the construction of the magnet according to their scientific and technological interests.

The experiment is installed at the interaction point number 5 at the LHC that includes a complex of surface buildings for pre-assembly activities and housing of the technical services.

In particular the main building, SX5, has been used to assemble the magnet and test it after provisional connection to its ancillaries like cryogenics and power converter.

At the end of the surface activities, the 11 elements of the magnet will be lowered in the experimental cavern using a large rented gantry crane of $2000 \mathrm{t}$. The heaviest piece to be lowered is the central barrel that houses the superconducting coil and part of the proximity cryogenics.

\section{MAin Design Options of THE SUPERCONDUCTING CoIL}

As pointed out in previous papers [3], [4] the CMS solenoid presents three new features with respect to previous detector magnets:

- Due to the high ampere-turns required for generating a field of $4 \mathrm{~T}$ (46.5 MA), the winding is composed of four layers, instead of the usual one (as in the Aleph or Delphi coils) or maximum two layers (as in ZEUS coil).

- The standard conductor, made from a Rutherford cable co-extruded with pure aluminium, is mechanically reinforced with aluminium alloy.

- The dimensions of the solenoid are very large $(6.3 \mathrm{~m}$ bore, $12.5 \mathrm{~m}$ length).

The basic new idea in the design of the CMS coil was to use a self-supporting conductor. The magnetic hoop stress (130 MPa) is shared between the layers (70\%) and the support cylindrical mandrel (30\%) rather than taken by the outer mandrel only, as it was the case in the previous generation of thin detector solenoids. This approach allows limiting the shear stress level inside the winding, especially at the interface between the windings and the -external mandrel. Nevertheless the construction of a winding using a reinforced conductor required technological developments for both the conductor [5] and the winding. In particular, for the winding we had to face many problems related to:

Mandrel construction: The mandrel, made of high strength aluminium alloy (5083-H321), is very thin (50 mm thickness for a diameter of $7 \mathrm{~m}$ ) and this brought severe construction problems regarding the cylindricity requirements [6].

Winding method: The CMS conductor is so stiff (the momentum of inertia is as high as $4.7210^{-7} \mathrm{~m}^{4}$ ) that to have an acceptable winding quality we developed a bending device that was able to impose a constant radius within $10 \mathrm{~mm}$ with a bending moment of $4400 \mathrm{Nm}$. Furthermore a dedicated fully 
automated device was developed for a precise positioning of the turns into the winding [4].

The coil is made of 5 modules, mechanically coupled and electrically connected in series ( 21 electrical joints). This option was extensively discussed in the design phase and compared with a completely different approach based on the construction on CERN site of the complete coil in one go. A monolithic coil has the advantage that no mechanical coupling between modules is required and that the electrical joints are reduced to 5 . Nevertheless the requirement of long conductor lengths (about $11 \mathrm{~km}$ for each layer), the risk related to the impregnation of a single very large object and the organization problems related to the set-up of a winding factory at CERN-P5 led to cancel this option in favor of a modular construction that, however, brought problems in relation to:

Impregnation: Each module required about 10001 of resin for the vacuum impregnation. An un-transportable autoclave was built close to the winding area.

Module to module mechanical mounting: The modules were mechanically connected by bolting the flanges of the mandrels. The crucial point was to have equal modules in dimensions (a maximum difference of $5 \mathrm{~mm}$ was allowed between maximum and minimum diameter). For larger spreads, the mounting would be hindered due to the lack of fitting between the side flanges. Furthermore the contact surfaces should be flat and no voids were allowed, as the $12000 \mathrm{t}$ axial compressing force would create dangerous movements if voids between two adjacent modules were present. To obtain a satisfactory contact surface, the top surface of each impregnated module was machined using a special lathe able to handle the modules (50 t, $7 \mathrm{~m}$ outer diameter).

Transportation: Each module was enclosed in a large transport box $(7.4 \mathrm{~m} \times 7.4 \mathrm{~m} \times 3 \mathrm{~m})$ and transported partly by boat and partly by road. The dimensions were at the limit allowed for road transportation.

\section{YoKe COMMISSIONING AND ClOSING}

The Yoke is composed of 11 large elements, 6 end-cap disks and 5 barrel wheels, whose weight goes from $400 \mathrm{t}$ for the lightest up to $1920 \mathrm{t}$ for the central wheel which includes the coil and its cryostat.

The relative movement of these elements allows and facilitates the assembly of the sub-detectors. To displace each element a combination of heavy-duty air pads plus grease pads has been chosen. This choice makes the system insensitive to metallic dust on the floor and allows precise transversal displacements.

Heavy-duty high-pressure air pads with a capacity of $250 \mathrm{t}$ and $385 \mathrm{t}$ each are used. The nominal pressure is respectively 40 and 60 bars. They include a rubber unit that reduces air losses to a minimum but increases the friction. Due to the aircushion, the load lifts by up to $20 \mathrm{~mm}$. This is not favorable for the final approach when closing the detector, especially for the YE1 endcap that is protruding into the vacuum tank. A special solution has been adopted: for the last $100 \mathrm{~mm}$ of approach, flat grease-pads (working pressure 100 bars) have been developed in order to facilitate the final closing of the detector. Once touching the axially installed z-stops, each element is pre-stressed with

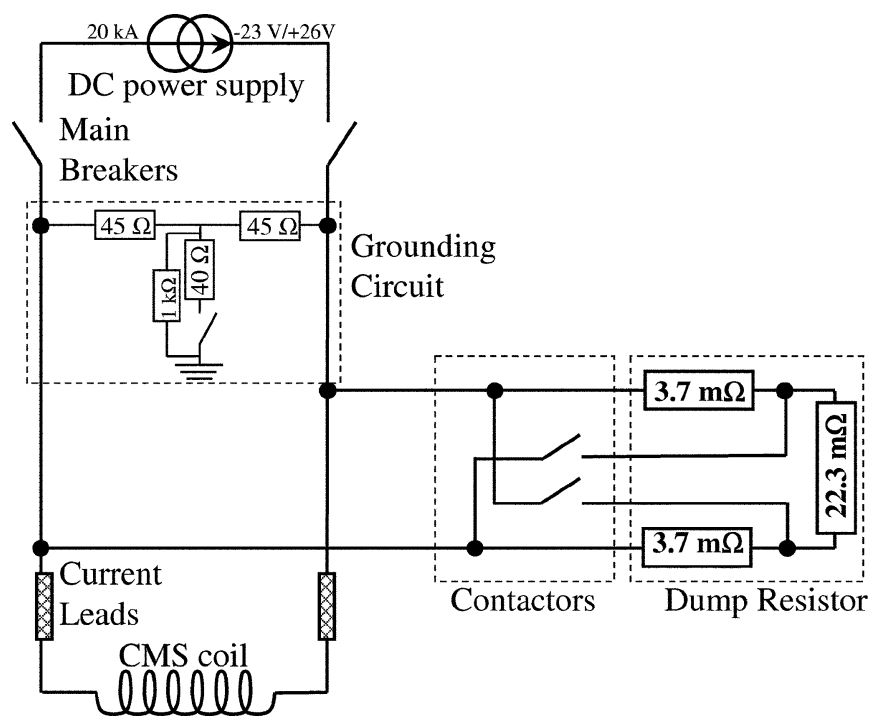

Fig. 1. Electrical circuit schematics.

$100 \mathrm{t}$ to the adjacent element. This assures good contact before switching on the magnet.

In the cavern the elements will be moved on the $1.23 \%$ inclined floor by a strand jacking hydraulic system that assures safe working for uphill pulling as well as for downhill pushing by keeping a retaining force. The maximum movements possible in the cavern are of the order of 11 meters; this will take one hour.

\section{A. Alignment}

In order to have a good alignment of the yoke elements, a precise reference network made of about 70 points has been installed in the surface assembly hall. The origin of the reference system is the geometrical center of the coil that corresponds to the particle interaction point. The measures were done after having loaded the coil cryostat with inner detector, the hadronic barrel in particular which weighs $1000 \mathrm{t}$. A check and marking on the floor of the position of each foot has been done to preposition each element within $\mathrm{a}+/-5 \mathrm{~mm}$ tolerance. Finally all the elements have been aligned with an accuracy of $1 \mathrm{~mm}$ with respect to the ideal axis of the coil.

\section{Electrical AND PRotection System}

\section{A. Protection Circuit}

The baseline of the protection circuit design is reliability. The components are oversized to get long holding time in case of fault such as lack of coolant. The switch breakers and the safety chains are doubled. Furthermore there is no active system included in the circuit, as shown in Fig. 1, such as heaters, and the dump resistor is always connected to the coil. Voltage test value of all power parts is $3 \mathrm{kV}$, for an operation value of $600 \mathrm{~V}$.

1) Discharge Modes: There are three modes: the normal one is using the reverse voltage of the power converter, a slow discharge (SD) on a $2 \mathrm{~m} \Omega$ resistance and a fast discharge (FD) on a $30 \mathrm{~m} \Omega$ resistance. During normal operation the resistor is put in parallel with the coil, with respect to the power supply, while 
during a discharge the power converter is disconnected, therefore leaving the coil in series with the dump resistor in a L-R type circuit. The SD heat-load on the cold mass, not larger than $525 \mathrm{~W}$, is fully absorbed by the refrigerator and the coil stays at $4.5 \mathrm{~K}$. All the magnetic energy is dissipated in the external dump resistor. This is the mode of decreasing the solenoid current to zero in case of fault of the power supply. The current discharge evolution is a pure exponential and its time constant is $7025 \mathrm{~s}$. The FD is the emergency mode of discharging the solenoid in case of major fault. The quick variation of the flux during a FD results in the quench back mechanism. The FD discharge time-constant is about $200 \mathrm{~s}$. A maximum voltage of $600 \mathrm{~V}$ is generated across the coil terminals, with a maximum voltage value of $\pm 300 \mathrm{~V}$ to ground.

2) DC Power Supply: A bipolar thyristor power converter rated at $520 \mathrm{~kW}$ with passive L-C filters is used to power the CMS solenoid. It covers a range of voltages from $+26 \mathrm{~V}$ to $-23 \mathrm{~V}$, with a nominal DC current of $20 \mathrm{kA}$. In case of a sudden switch-off of the power converter, the current decays naturally in the bus-bar resistance and through the free-wheel thyristors until the opening of the main breakers. Inside the power converter, an assembly of free-wheel thyristors, mounted on naturally aircooled heat sinks, is installed. In case of non-opening of the main switch breakers, the thyristors are rated to support $20 \mathrm{kA}$ DC for 4 minutes.

3) Main Breakers: The discharge is obtained by acting on both main switch breakers, each of them comprising 6 high capacity poles put in parallel on a single mechanical shaft. The breakers are normally opened and naturally air-cooled. The closing and holding is done by DC coils. Each pole has a nominal continuous current capacity of $6.2 \mathrm{kA} \mathrm{DC}$. Each single pole is able to open the full load of $20 \mathrm{kA}$ and $600 \mathrm{~V} \mathrm{DC}$.

4) Dump Resistor: The dump resistor is composed of three main modules either in series for the FD mode or in parallel for the SD mode. The change of configuration is obtained by a redundant set of contactors of the same type than the main breakers. In all operational phases, but the SD, the contactors are opened, leaving the dump resistor in FD configuration. The resistor, made from stainless steel, is installed outdoor and naturally air-cooled. During a FD, the average temperature increase is less than $300^{\circ} \mathrm{C}$. It is less than $200^{\circ} \mathrm{C}$ for a SD. The total inductance of the resistor system is about $10 \mu \mathrm{H}$.

5) Busbar Systems: The $20 \mathrm{kA}$ electrical lines connecting the power supply to the coil are made of air-cooled copper bars and water-cooled high purity aluminium tubes. The tubes are used in low accessibility zones with poor ventilation and have welded connections. The cross-section is larger than $20000 \mathrm{~mm}^{2}$ to limit both the voltage drop to less than $2 \mathrm{~V}$ and the Joule dissipation. To ensure the electrical continuity of the lines between the solenoid and the dump resistor, the lines are designed to withstand the full current in case of lack of coolant with a temperature increase less than $20^{\circ} \mathrm{C}$ per hour. The layout of the aluminum discharge lines minimizes their inductance to $0.2 \mu \mathrm{H} / \mathrm{m}$, with a total resistance of $0.3 \mathrm{~m} \Omega$.

6) Current Leads: The two $20 \mathrm{kA}$ current leads are made of a high purity copper braid, having a section of $1800 \mathrm{~mm}^{2}$ and a RRR of 130, placed inside a conduit and cooled by circulating helium gas. The current leads are able to hold a current of 20
$\mathrm{kA}$ during 5 minutes followed by a FD without any damage, as the temperature at the hot spot stays below $400 \mathrm{~K}$ [7].

7) Grounding Circuit: The grounding circuit is connected across the solenoid terminals. It fixes the coil circuit potential, through a $1 \mathrm{k} \Omega$ resistor, dividing by two the potential to ground The winding insulation quality is monitored by continuously measuring the leak current through a $10 \Omega$ grounding resistor. This allows also detecting a coil short-circuit to ground. A relay triggers the ramp down of the coil current in case the leak current reaches a maximum absolute value of $150 \mathrm{~mA}$.

8) Electrical Joints: The electrical connections between layers or modules have been studied with 3D Finite Element Method (FEM) analysis in order to estimate their temperature increase in case of discharge. The maximal temperature computed is $370 \mathrm{~K}$, which cannot deteriorate the insulation. Nevertheless, all joints were over-stabilized with aluminum alloy.

9) Quench Detection System: The quench detection system is a key element of the Magnet Safety System (MSS). The role of the quench detection system is to detect a resistive voltage between two points of the coil, whose value and duration are compared to adjustable thresholds. The voltage taps are protected by $4.7 \mathrm{k} \Omega, 6 \mathrm{~W}$ resistors. There are two redundant systems, with resistor bridge detectors and differential detectors. For each system, there are five detectors. Each resistor bridge detector spans two modules and one detector spans the whole solenoid. With the differential detector, each coil module is compared with two other modules through two differential detectors.

\section{COMMISSIONING OF THE ANCILLARIES}

\section{A. The Vacuum System}

The vacuum system was designed to provide a good insulation inside the vacuum volume of $40 \mathrm{~m}^{3}$ of the coil cryostat. It consists of two double primary pumping stations, equipped with two rotary pumps and two roots pumps, which provide the fore vacuum to the two oil diffusion pumps located at the top of CMS and connected to the coil cryostat via the current leads chimney and the helium phase separator.

The rotary pumps have a pumping speed of $280 \mathrm{~m}^{3} / \mathrm{h}$ while the two roots have a flow of $1000 \mathrm{~m}^{3} / \mathrm{h}$. The biggest oil diffusion pump, installed via a DN 400 flange on the current leads chimney, has a nominal flow of $8000 \mathrm{l} / \mathrm{s}$ at $10^{-4} \mathrm{mbar}$ of fore vacuum. The smallest one delivers $3000 \mathrm{l} / \mathrm{s}$ at the phase separator. The system has been installed in November 2005.

The commissioning took a couple of months, and since January this year it is working in a stable and reliable configuration.

The insulation vacuum is about $10^{-5}$ mbar when the coil is warm and $10^{-6}$ mbar when the huge cold mass acts as a cryogenic trap for gases other than helium. Special precautions have been taken to protect sensitive pressure gauges from magnetic stray field.

\section{B. The External Cryogenic Plant}

The Helium refrigeration plant for CMS is specified for a cooling capacity of $800 \mathrm{~W}$ at $4.45 \mathrm{~K}, 4500 \mathrm{~W}$ between 60 and $80 \mathrm{~K}$ and $4 \mathrm{~g} / \mathrm{s}$ liquefaction capacity simultaneously. 


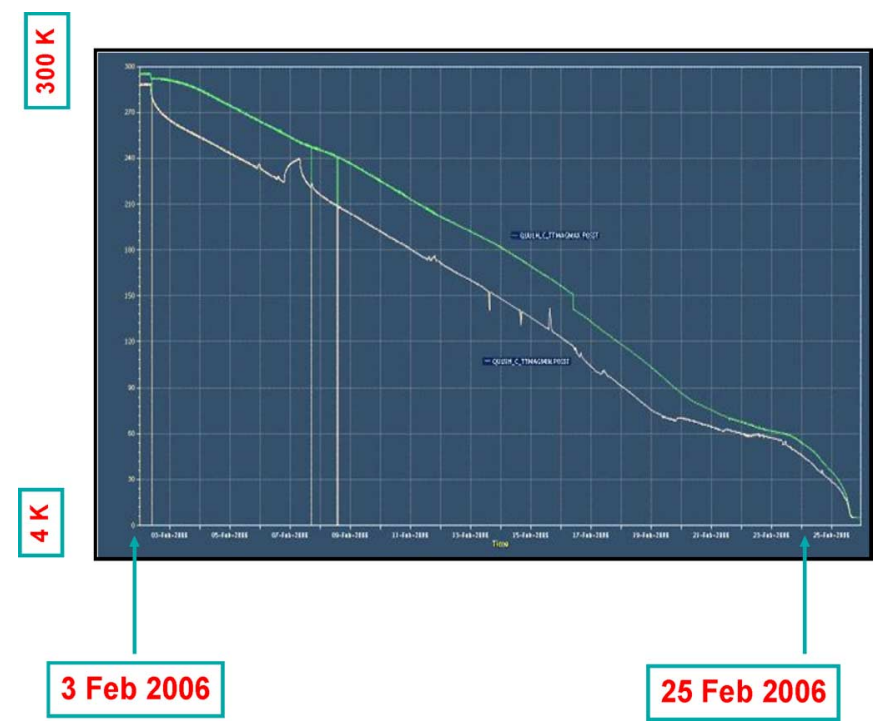

Fig. 2. Graph of the coil minimum and maximum temperatures during the cooldown to $4.5 \mathrm{~K}$

The primary compressors of the plant are installed in their final position, while the cold box as well as the intermediate cryostat which interfaces the phase separator and the thermoshyphon will be placed underground after the completion of the magnet test.

The compressor station was commissioned already in 2002, and the major problem encountered was due to an oil pollution that required the installation of an additional oil coalescer.

The cold box was commissioned in 2003, and its major problems were related once again with oil pollution (removed by alcohol cleaning) and by the commissioning of the third stage turbine that showed persistent problems at start-up.

These components were commissioned with the help of a temporary heat load of $6.5 \mathrm{~kW}$ that simulated the coil cryostat not yet ready. In March 2005 the original control system was replaced by the PVSS system adapted to the CERN wide cryogenic control standards.

The performance of the cold box has been measured in cooldown mode and in nominal operation mode.

The cool down of the real coil started on 2 February 2006 and in an exceptionally smooth way brought the cold mass to $4.6 \mathrm{~K}$ in 28 days. Fig. 2 shows the cool down curve. The only glitch was due to an overpressure on a safety release valve that stopped cooling during one night before restarting the system.

\section{MAGNETIC TESTS}

Before carrying out the magnetic tests, the yoke needed to be closed. Since the magnet is fully integrated into the whole detector, it was necessary to wait for a complete assembly of a substantial number of detectors before starting the magnetic test. Fig. 3 shows how the magnet appeared just before the final yoke closing.

The magnetic tests took place during August 2006. The tests were carried out through magnet charges to progressively higher currents, followed by slow or fast discharge. During these current cycles all the relevant parameters related to electrical, magnetic, thermal and mechanical behaviors have been recorded.

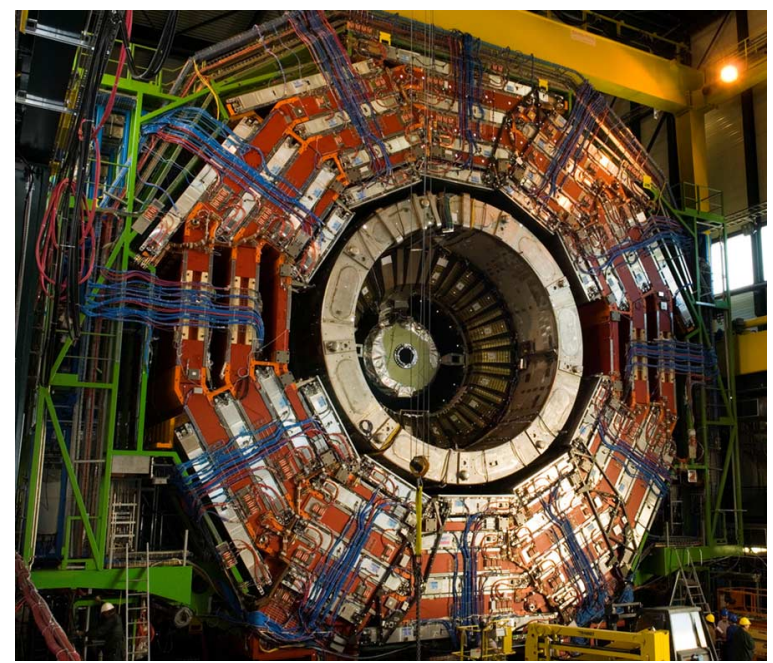

Fig. 3. The superconducting coil in its cryostat, containing in the inner bore the tracker, the electron calorimeter and the barrel hadron calorimeter, surrounded by the barrel yoke equipped with muon detectors.

The performed current cycles were: 1) ramp up \& down at $3.2 \mathrm{kA}$ with power converter; 2) Sequence of ramp-up and fast discharge at $2 \mathrm{kA}, 7.5 \mathrm{kA}, 12.5 \mathrm{kA}, 15 \mathrm{kA}, 17.5 \mathrm{kA}$ and 19144 A (corresponding to the target field of $4.0 \mathrm{~T}$ in the center of the magnet).

Each time the solenoid is fast discharged, the eddy currents generated in the mandrels cause a quench of the whole coil (quench back), which prevents local overheating. Depending on the level of the current the time needed for re-cooling the coil can be up to 3 days. Some details of the tests are discussed in the following sections.

\section{A. Mechanical Instrumentation on the Cold Mass}

Fig. 4 shows a scheme of the coil supporting system, made of longitudinal, vertical and axial tie-rods in Ti alloy.

The tie-rods are loaded in tension and flexion. To measure the tension and flexion strain, 3 strain gauges are placed on the tie rods at $0^{\circ}, 90^{\circ}$ and $180^{\circ}$. A fourth one is placed in a perpendicular direction to compensate the potential thermal and magnetic measurement disturbances.

Twelve displacements sensors are used to measure the position of the cold mass with respect to the cryostat. Eight give the radial displacements and four the longitudinal displacements. The sensor bodies are fixed on the cold mass. The movable part of the sensor is pushed against the cryostat using a spring.

Three sets of strain gauges are fixed on the cold mass to measure the stresses during coil energization. Another set is glued on one non-stressed aluminum plate to compensate the potential thermal and magnetic measurement disturbances.

During the coil cool-down, the cold-mass shrinkage and the tie-rod stress increase have been checked. The mean shrinkage and stresses due to cool-down are reported in Table I, showing that the measured values are in good agreement with the calculated ones.

\section{B. Cold Mass Misalignment}

The support system is designed to withstand the forces created by a $10 \mathrm{~mm}$ magnetic misalignment of the cold mass with respect 


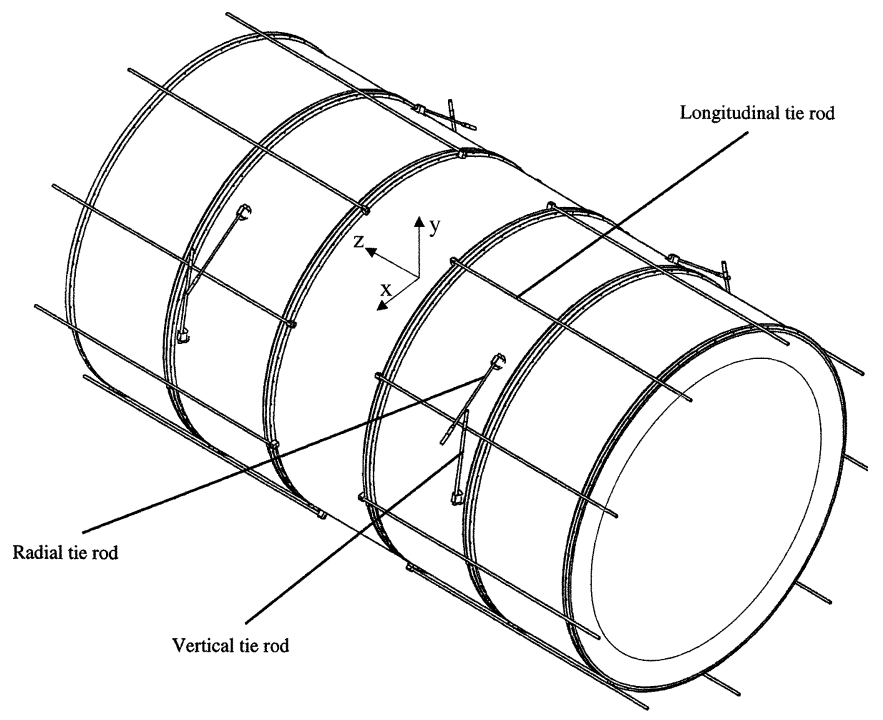

Fig. 4. The supporting system of the cold mass in the vacuum tank.

TABLE I

Calculated and Measured Cold Mass Displacements and Related StResses on TIE-Rods Due to THE CoOldown to $4.5 \mathrm{~K}$

\begin{tabular}{ccc}
\hline \hline & Expected value & Measured value \\
\hline $\begin{array}{c}\text { Cold Mass Shrinkage } \\
\text { Longitudinal } \\
\text { Radial }\end{array}$ & $26 \mathrm{~mm}$ & $27 \mathrm{~mm}$ \\
Tie rod stress due to cool- & $14 \mathrm{~mm}$ & $15 \mathrm{~mm}$ \\
down & & \\
Vertical & $50 \mathrm{MPa}$ & $47 \mathrm{MPa}$ \\
Radial & $150 \mathrm{MPa}$ & $156 \mathrm{MPa}$ \\
Longitudinal & $250 \mathrm{MPa}$ & $234 \mathrm{MPa}$ \\
\hline \hline
\end{tabular}

to the iron yoke in any direction. Geometrical survey has been performed at each step of the magnet assembly to insure a good positioning. Nevertheless, the monitoring of the coil magnetic misalignment is of prime importance during magnet power test.

The powering of the cold mass has been performed step by step. The analysis of the coil misalignment at full current is reported hereafter.

The misalignment can be calculated either by analyzing the displacement of the cold mass or the stresses of the tie rods when the coil is energized. The misalignments are reported in Table II for a set of measurements at full current. One can see that in all cases, the misalignments are much less than the $10 \mathrm{~mm}$ maximal value and that the two approaches lead to consistent estimations.

Using the strain gauges glued on the cold mass (outer mandrel of central module, CB0), one can determine the stresses. The curves of the cold mass stresses vs coil current is given in Fig. 5. The measured value of Von Mises stress at $4.5 \mathrm{~K}$ and zero current is $23 \mathrm{MPa}$. The value at $19.1 \mathrm{kA}$ is $138 \mathrm{MPa}$. These values are in agreement with computations done during design [8], [9].

\section{Electrical Measurements}

The coil inductance measured through the inductive voltage $\mathrm{V}=\mathrm{L} \mathrm{dI} / \mathrm{dt}$ is varying while increasing the current, as the
TABLE II

Cold Mass Misalignment ObTaINED From Displacements and StResses AT $19.1 \mathrm{kA}$

\begin{tabular}{ccc}
\hline \hline & $\begin{array}{c}\text { From analysis of } \\
\text { cold mass } \\
\text { displacements }\end{array}$ & $\begin{array}{c}\text { From analysis of } \\
\text { tie rod stress }\end{array}$ \\
\hline Coil axis direction & $1.50 \mathrm{~mm}$ & $2.40 \mathrm{~mm}$ \\
Perpendicular to coil axis & $0.25 \div 2.5 \mathrm{~mm}$ & $2.5 \div 3.0 \mathrm{~mm}$ \\
$\begin{array}{c}\text { (Horizontal direction) } \\
\text { Perpendicular to coil axis } \\
\text { (Vertical direction) }\end{array}$ & $1.20 \div 0.45 \mathrm{~mm}$ & Not measurable \\
\hline \hline
\end{tabular}

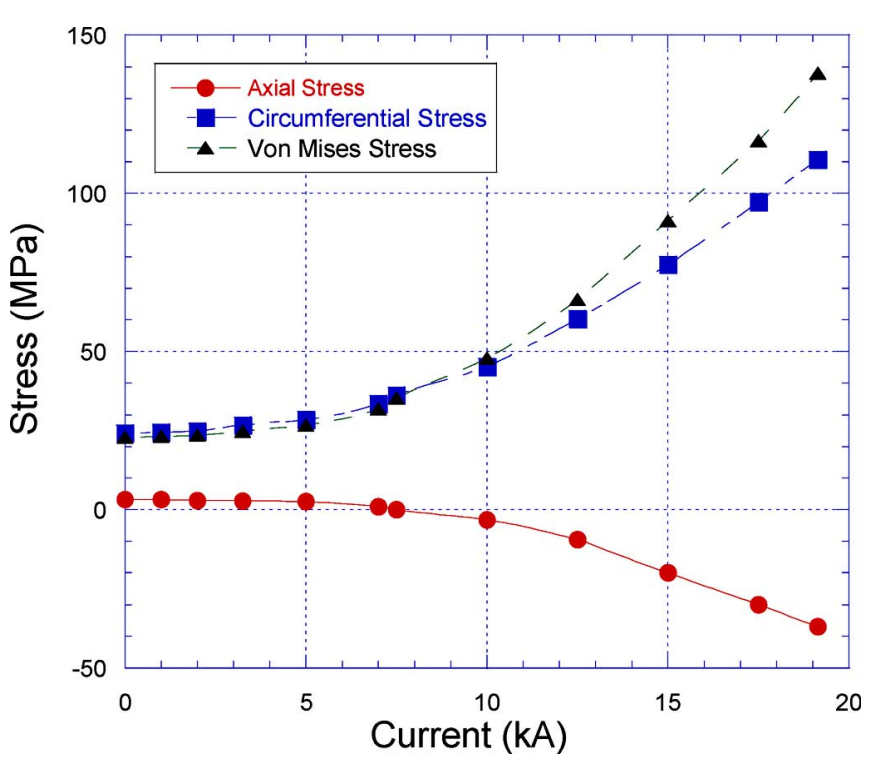

Fig. 5. Stresses measured on CB0 module as function of the current. (Full circles represent axial stress, full squares represent circumferential stress and full triangles represent Von Misers stress).

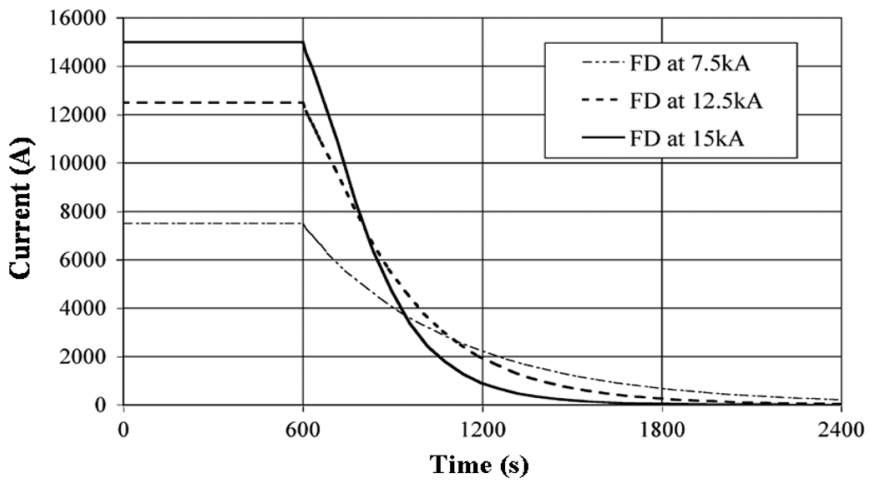

Fig. 6. Magnet current fast discharge at various initial currents.

iron yoke reaches saturation region. The inductance of the coil is $14.1 \mathrm{H}$ at zero current and decreases to $13 \mathrm{H}$ at $19 \mathrm{kA}$.

The 21 electrical joints, placed externally to the coil, have each one a resistance ranging from $0.7 \mathrm{n} \Omega$ to $1.6 \mathrm{n} \Omega$ at $19 \mathrm{kA}$ corresponding to a maximum dissipation $0.6 \mathrm{~W}$ per joint. This heating is not causing any temperature increase due to the heat removal system.

As mentioned above, the fast discharge causes a quench of the coil, through quench-back process. The effect of both the dump 
resistor and the magnet electrical resistance increase is visible on the discharge time constant (Fig. 6): $\tau=\mathrm{L} / \mathrm{R}$ is equal to $266 \mathrm{~s}, 348 \mathrm{~s}$ and $491 \mathrm{~s}$ for fast discharges respectively at $15 \mathrm{kA}$, $12.5 \mathrm{kA}$ and $7.5 \mathrm{kA}$. The average cold mass temperature after a fast discharge at $19 \mathrm{kA}$ is $70 \mathrm{~K}$, corresponding to half of the total energy $(1250 \mathrm{MJ})$ dissipated as heat in the coil.

\section{CONCLUSIONS}

After 15 years from early design and first R\&D, pre-industrialization activities, 7 years of construction and about one year of installation, CMS magnet is now under commissioning. From cryogenic, electrical and mechanical tests the coil looks to fulfill all specifications. After a period for field mapping, the magnet and detectors will be installed into the cavern and ready for the physics in October 2007.

\section{ACKNOWLEDGMENT}

The authors acknowledge all colleagues having participated in the challenging CMS magnet project during all phases of its development, from early R\&D to design and construction, requiring a large effort from several skilled and enthusiastic persons. In particular the authors retain a clear memory of the important contribution of recently deceased friends: Jean Claude Lottin of CEA, Richard Smith of Fermilab and Vitali Kaftanov of ITEP.

\section{REFERENCES}

[1] CMS Magnet Collaboration, The Magnet Project:Technical Design Report CERN, 1997, volume CERN/LHCC97-10, CMS TDR 1.

[2] A. Hervé, B. Blau, D. Campi, P. Cannarsa, B. Curé, P. Fabbricatore, S. Farinon, F. Feyzi, A. Gaddi, H. Gerwig, M. Greco, J. P. Grillet, V. Kaftanov, F. Kircher, V. Klyukin, B. Levésy, R. Loveless, G. Maire, R. Musenich, Y. Pabot, A. Payn, G. Perinic, P. Petiot, F. Rondeaux, H. Rykaczewski, E. Sbrissa, S. Sequeira Tavares, S. Sgobba, R. P. Smith, L. Veillet, and G. Waurick, "Status of the construction of CMS magnet," IEEE Trans. Appl. Supercon., vol. 14, no. 2, pp. 542-547, June 2004.

[3] A. Hervé, "The CMS detector magnet," IEEE Trans. Appl. Supercon., vol. 10 , no. 1 , pp. 389-394, 2000.

[4] P. Fabbricatore, D. Campi, C. D’Urzo, S. Farinon, A. Gaddi, B. Levésy, L. Loche, R. Musenich, F. Rondeaux, and R. Penco, "The construction of modules composing the CMS superconducting coil," IEEE Trans. Appl. Supercon., vol. 14, no. 2, pp. 552-555, June 2004.

[5] B. Blau, D. Campi, B. Curé, R. Folch, A. Hervé, I. L. Horvath, F. Kircher, R. Musenich, J. Neuenschwander, P. Riboni, B. Seeber, S. Sequeira-Tavares, S. Sgobba, and R. P. Smith, "The CMS conductor," IEEE Trans. Appl. Supercon., vol. 12, no. 1, pp. 345-348, Mar. 2002.

[6] S. Sgobba, C. D’Urzo, P. Fabbricatore, and S. Sequeira Tavares, "Mechanical performance at cryogenic temperature of the modules of the external cylinder of CMS and quality controls applied during their fabrication," IEEE Trans. Appl. Superconduct., vol. 14, no. 2, pp. 556-559, June 2004.

[7] P. Fazilleau, P. Brédy, F. P. Juster, F. Kircher, Y. Pabot, L. Scola, and B. Curé, "Design, construction and tests of the $20 \mathrm{kA}$ Current Leads for the CMS Solenoid," IEEE Trans. Appl. Superconduct., vol. 14, no. 2, pp. 1765-1769, June 2004.

[8] C. Pes, Internal Report CEA/DAPNIA N. 5C 2100 T -M 1000031 1998.

[9] P. Fabbricatore and S. Farinon, Summary of Mechanical Thermal and Magnet Analyses on CMS Cold Mass Made at INFN Genova During 1997 Report INFN/TC_98/10. 